\title{
Qualidade de mudas de pau-ferro produzidas em diferentes substratos e condições de luz
}

\author{
Laércio Wanderley dos Santos ${ }^{1}$, Maria de Fatima Barbosa Coelho², Rodrigo Aleixo Brito de Azevedo ${ }^{3}$ \\ ${ }^{1}$ Universidade Federal de Mato Grosso, Centro Universitário do Araguaia, Rod. MT 100, Km 3,5 Centro, CEP 78698-000, Pontal do Araguaia, MT, Brasil \\ ${ }^{2}$ Universidade Internacional da Integração da Lusofonia Afro Brasileira, Pro-reitoria de Graduação, Av da Abolição, 7, Centro, CEP 60115-082, Redenção, CE, Brasil \\ ${ }^{3}$ Universidade da Integração Internacional da Lusofonia Afro-Brasileira, Av. Abolição, 3, Centro, CEP 62790-000, Acarape, CE, Brasil
}

"Autor correspondente:
laerwan@gmail.com

Termos para indexação:

Caesalpinia ferrea

Características morfológicas

Produção de mudas

Esterco bovino

\section{Index terms:}

Caesalpinia ferrea

Morphological characteristics

Seedling production

Cattle manure

Histórico do artigo:

Recebido em 28/11/2011

Aprovado em 22/03/2013

Publicado em 28/06/2013

doi: 10.4336/2013.pfb.33.74.344
Resumo - O objetivo deste estudo foi avaliar o efeito de diferentes substratos e luminosidade no crescimento inicial de mudas de Caesalpinia ferrea Mart. Ex Tul. (pau-ferro). $\mathrm{O}$ delineamento experimental utilizado foi inteiramente casualizado em esquema fatorial $5 \times 2$ (cinco substratos e dois ambientes) com quatro repetições de 10 plantas na parcela. Os substratos foram: 1 -arisco; 2 -arisco + esterco bovino $2: 1$; 3 arisco + esterco bovino 3:1; 4- areia + esterco bovino $2: 1$; e 5 - areia + esterco bovino $3: 1$. Os ambientes foram a pleno sol e com $50 \%$ de luminosidade. Foram analisadas, em setembro de 2009, as características diâmetro do coleto, altura da planta, massa seca das raízes e da parte aérea, área foliar e índice de qualidade de Dickson. Não houve diferença significativa para o diâmetro do coleto. Os substratos com esterco bovino favoreceram o desenvolvimento em altura, massa seca de raízes e da parte aérea nos dois ambientes. A área foliar das mudas foi maior nos substratos com esterco e em condições de sombreamento. Mudas de melhor qualidade foram produzidas tanto em condições de $50 \%$ de luminosidade quanto a pleno sol. As mudas podem ser produzidas em substratos com esterco e a pleno sol.

\section{Quality of Caesalpinia ferrea seedlings produced on different substrates and light conditions}

\begin{abstract}
The aim of this study was to evaluate the effect of different substrates and luminosity in the early growth of Caesalpinia ferrea Mart. ex Tul. seedlings. It was used completely randomized design in factorial $5 \times 2$ (five substrates and two environments) with four replications of 10 plants in each plot. The substrates were 1- arisco, 2- arisco + cattle manure 2:1, 3- arisco + cattle manure 3:1, 4- sand + cattle manure 2:1 and 5sand + cattle manure 3:1. Environments were in full sun and 50\% light. The evaluated characteristics in September 2009, were stem diameter, height, roots dry mass, shoots dry mass, leaf area and index quality of Dickson. There was no significant difference for stem diameter. The substrates containing manure promoted the development in height, dry mass of roots and shoots in both environments. Leaf area of seedlings was greater in shaded conditions and substrates with manure. The best quality seedlings were produced in $50 \%$ light or full sun. The seedlings should be produced on substrates containing cattle manure and conditions of full sun.
\end{abstract}




\section{Introdução}

O uso de espécies florestais nativas para enriquecimento de matas, recuperação de áreas degradadas e fornecimento de matéria prima para fitoterápicos é ainda dificultado, em grande parte, pela carência de informações sobre as condições de produção de mudas dessas espécies. Este fato faz com que na recuperação ou restauração de ambientes degradados sejam frequentemente usadas espécies como Acacia holocericea e Acacia mangium, que são leguminosas de origem exótica, a despeito da grande diversidade de leguminosas nativas que do Brasil (Gonçalves et al., 2010).

A primeira fase do cultivo de espécies arbóreas consiste na obtenção de sementes selecionadas para a produção de mudas vigorosas e isentas de pragas e doenças. $\mathrm{O}$ conhecimento das condições de sombreamento e substratos contribui para a obtenção de mudas de melhor qualidade. Neste sentido, Santarelli (2001) e Moraes Neto \& Gonçalves (2001) ressaltaram a importância do estudo sobre o efeito da luminosidade na produção de mudas de espécies nativas na fase de viveiro.

A produção de mudas em viveiros constitui uma das fases mais importantes do processo de implantação de povoamentos florestais, pois mudas de baixa qualidade podem comprometer todas as operações seguintes (Costa et al., 2008). Um dos principais problemas dos produtores de mudas de espécies florestais é determinar, durante a fase de viveiro, os fatores que alteram a sobrevivência e o desenvolvimento inicial das mudas no campo, bem como as características fisiológicas da planta que melhor apresentam melhor correlação com essas variáveis (Lima et al., 2008).

A formação de mudas mais vigorosas permite maior chance de sucesso no estabelecimento da cultura. Isto pode ser alcançado de maneira prática, rápida e fácil, observando-se características morfológicas (Fonseca et al., 2002), que são mais usuais em relação às fisiológicas, ou realizando análises do crescimento em mudas sob diferentes condições de luminosidade, nutrientes e água.

A luminosidade, por sua vez, controla os processos responsáveis pelo acúmulo de matéria seca, contribuindo para o crescimento das mudas. O estudo da luminosidade é fundamental para a avaliação do potencial dessas espécies em programas de revegetação, pois a disponibilidade de luz constitui um dos fatores críticos para o seu desenvolvimento (Almeida et al., 2005). Desta forma, a eficiência do crescimento pode ser relacionada à habilidade de adaptação das mudas às condições luminosas do ambiente, sendo o crescimento satisfatório de algumas espécies em ambientes com baixa ou alta luminosidade atribuído à capacidade da espécie em ajustar rapidamente seu modelo de alocação de biomassa e comportamento fisiológico (Dias Filho, 1997).

O substrato é o meio em que as raízes se desenvolvem, visando à garantia de um suporte estrutural, fornecendo água, oxigênio e nutrientes para que as mudas se desenvolvam (Oliveira et al., 2005). Inúmeras matérias primas em sua constituição original ou combinada são usadas atualmente para propagação de vegetais.

$\mathrm{Na}$ escolha do substrato ideal para a espécie devemse observar, principalmente, suas características físicas e químicas, além da relação custo/benefício e disponibilidade no mercado. Negreiros et al. (2004) salientaram a conveniência da associação de materiais orgânicos, especialmente em mistura com o solo, para melhorar a textura do substrato e, dessa maneira, propiciar boas condições físicas, além de fornecer os nutrientes necessários ao desenvolvimento das raízes e da muda.

Em áreas da Caatinga, onde há disponibilidade de matéria orgânica, os produtores adicionam esterco aos solos (Salcedo \& Sampaio, 2008). O esterco bovino melhora os aspectos químicos, físicos e biológicos do solo e aumenta a estabilidade de agregados e a retenção de água, favorecendo a disponibilização dos nutrientes (Santos \& Coelho, 2008).

Algumas espécies da Caatinga têm se destacado em estudos que avaliam sua utilização em processos de recuperação e em sistemas agrícolas que envolvam plantas de múltiplos usos. A Caesalpinia ferrea Mart. ex Tul. (=C. ferrea var. cearensis) é uma espécie arbórea que ocorre do Ceará à Bahia, na Caatinga arbórea e arbustiva. Tem uso medicinal, madeireiro, ornamental, tintorial, forrageiro, entre outros (Ducke, 1953; Maia, 2004). Esta espécie tem tronco tortuoso e sempre mais baixo, até $10 \mathrm{~m}$ de altura em relação a outras variedades desta espécie. É semelhante ao jucá (Caesalpinia ferrea var. ferrea), mas não ao pau-ferro da mata do Rio de Janeiro e das serras do Nordeste (Ducke, 1953; Maia, 2004).

A parte interna da casca do caule (endoderme) e os frutos são usados no nordeste do Brasil como adstringente, antidiabético e também para combater diarréia e sangramento. O extrato hidroalcoólico dos frutos tem comprovada ação anti-inflamatória, 
imunoestimulante, hiperglicemiante e inibitória dos tumores (Lorenzi \& Matos, 2008).

Entretanto, espécies tão importantes como jucá correm o risco de extinção antes do estabelecimento de cultivos, pois a atividade humana direta ou indireta tem causado o desaparecimento de espécies (Fachim \& Guarim, 1995). As áreas desmatadas no nordeste brasileiro, por causa do corte de lenha para carvão e estacas na Caatinga, atingem, aproximadamente, $10 \mathrm{mil}$ $\mathrm{km}^{2}$, computando-se unicamente os estados do Ceará, Rio Grande do Norte, Paraíba e Pernambuco (Salcedo \& Sampaio, 2008).

Além disso, as mudas desta espécie que se formam sob o dossel da planta mãe são forrageadas (Maia, 2004), principalmente por caprinos e bovinos. Desta forma, a espécie corre perigo de diminuição drástica, em médio prazo, pela falta de estabelecimento de novas plantas.

Assim, o objetivo deste trabalho foi avaliar o efeito de diferentes substratos e ambientes na produção de mudas de Caesalpinia ferrea em viveiro.

\section{Material e métodos}

O trabalho foi conduzido de junho a setembro de 2009, no viveiro do Departamento de Ciências Vegetais, Campus da Universidade Federal Rural do Semi Árido (UFERSA), localizado em Mossoró, RN, cujas coordenadas geográficas são $5^{\circ} 11^{\prime} \mathrm{S}$ e $37^{\circ} 20^{\prime} \mathrm{W}$, com altitude de $18 \mathrm{~m}$ (Silva et al., 2002). O clima da região, de acordo com a classificação de Köppen, é BSwh, seco e muito quente, com duas estações climáticas: uma seca, de junho a janeiro, e uma chuvosa, de fevereiro a maio (Barros Júnior, 2005).

As sementes de jucá usadas no experimento foram extraídas de frutos coletados em árvores do campus da UFERSA em maio de 2009. Para a quebra da dormência das sementes foi utilizado o método de escarificação do lado oposto ao hilo com lixa de $n^{\circ} 60$.

O delineamento experimental foi inteiramente casualizado em esquema fatorial $5 \times 2$, cinco substratos e dois ambientes (pleno sol e $50 \%$ de luminosidade), com quatro repetições de 10 plantas na parcela. Os substratos foram compostos por diferentes proporções volumétricas dos materiais que se seguem: 1- arisco; 2arisco + esterco bovino (2:1); 3- arisco + esterco bovino (3:1); 4- areia + esterco bovino (2:1) e 5- areia + esterco bovino (3:1). Os ambientes foram $50 \%$ de luminosidade, em viveiro com tela de polietileno de cor preta, e pleno sol, instalado do lado de fora do viveiro. Os substratos foram analisados quimicamente no Laboratório de Solos da UFERSA (Tabela 1). Para a produção das mudas foram utilizadas sacolas de polietileno, nas dimensões de $15 \mathrm{~cm}$ x $25 \mathrm{~cm}$.

Para cada tratamento, foram utilizadas quarenta sacolas dispostas em fileiras de dez sacolas. Cada fileira constituiu a parcela, sendo acondicionada uma semente em cada sacola, totalizando, no final do experimento, duzentas mudas para cada ambiente. As sacolas foram dispostas uma ao lado das outras, havendo separação apenas entre os tratamentos. Durante a condução do experimento, foi realizada uma irrigação por dia e catação manual de plantas invasoras e larvas de insetos.

$\mathrm{O}$ arisco, termo utilizado para esse tipo de solo na região Nordeste do Brasil, também conhecido como saibro em outras regiões, é definido pela Associação Brasileira de Normas Técnicas (ABNT) como solo proveniente de granitos e gnaisses, com minerais parcialmente decompostos, sendo arenosos ou siltosos, com baixo teor de argila e de cor variada (Mattos, 2001)

Aos 80 dias após a semeadura foram analisadas as seguintes características: diâmetro à altura do coleto

Tabela 1. Características dos substratos utilizados na produção de mudas de Caesalpinia ferrea em Mossoró, RN, 2009.

\begin{tabular}{|c|c|c|c|c|c|c|c|c|}
\hline \multirow[t]{2}{*}{ Substratos } & pH & $\mathbf{P}$ & $\mathbf{K}^{+}$ & $\mathrm{Na}^{+}$ & $\mathrm{Ca}^{2+}$ & $\mathrm{Mg}^{2+}$ & $\mathbf{A l}^{3+}$ & \multirow[t]{2}{*}{$\mathbf{C} / \mathbf{N}$} \\
\hline & (água) & \multicolumn{3}{|c|}{$\mathrm{mg} \mathrm{dm}^{-3}$} & \multicolumn{3}{|c|}{ cmolc dm dm $^{-3}$} & \\
\hline Arisco & 5,8 & 1,9 & 26,2 & 16,7 & 1,8 & 2,4 & 0,05 & - \\
\hline Arisco + Esterco $(2: 1)$ & 7,1 & 65,9 & 550,1 & 127,3 & 2,1 & 2 & 0 & 3,99 \\
\hline Arisco + Esterco $(3: 1)$ & 6,9 & 92,3 & 355,5 & 82,7 & 1,6 & 1,4 & 0 & 4,54 \\
\hline Areia + Esterco $(2: 1)$ & 7,6 & 152,1 & 461,5 & 96,9 & 2,1 & 1,6 & 0 & - \\
\hline Areia + Esterco (3:1) & 7,7 & 108,3 & 223,8 & 62,4 & 2 & 2,2 & 0 & - \\
\hline
\end{tabular}

Fonte: Laboratório de Fertilidade do Solo e Nutrição de Plantas da UFERSA. 
$(\mathrm{mm})$, altura da parte aérea da planta $(\mathrm{cm})$, massa seca das raízes e da parte aérea $(\mathrm{g})$, área foliar $\left(\mathrm{cm}^{2}\right)$ e índice de qualidade de Dickson. A matéria seca foi obtida, após a secagem em estufa, por meio de uma balança analítica modelo ACCULAB Sartorius group.

Em seguida, determinou-se a área foliar das mudas pelo método do disco (Fernandes, 2000). O índice de qualidade de Dickson (IQD) foi determinado pela equação: IQD = MST/(H/D + MSPA/MSR) (Dickson et al., 1960), sendo: IQD = índice de qualidade de Dickson; $\mathrm{MST}=$ massa seca total; $\mathrm{H}=$ altura da planta; $\mathrm{D}=$ diâmetro do coleto; MSPA = massa seca da parte aérea; MSR = massa seca da raiz.

A partir dos dados primários foram determinadas a razão H/D (altura da planta/diâmetro do coleto) e a razão MSPA/MSR (massa seca da parte aérea/massa seca da raiz).

A análise dos dados foi realizada usando-se o programa SAEG - Sistema para Análises Estatísticas e Genéticas - versão 9.1 (Ribeiro Junior \& Melo, 2009), obtendo-se análise de variância e teste de médias (Scott Knott ao nível de 5\% de probabilidade).

\section{Resultados e discussão}

Não houve diferença estatística significativa para o diâmetro do coleto entre os diferentes substratos e ambientes (Figura 1). Este resultado, difere do relatado para a mesma espécie por Lima et al. (2008). Estes autores verificaram variação entre os tratamentos, havendo tendência de redução nesta característica, com o aumento do sombreamento. No entanto, neste trabalho, a coleta dos dados iniciou-se aos 80 dias após a semeadura, e as condições de luz foram pleno sol e $50 \%$ de luminosidade; e no trabalho realizado por Lima et al. (2008), o período utilizado foi de 90 dias após a semeadura, e as condições de luz foram Pleno sol, 50\% de luminosidade, $70 \%$ de luminosidade e sombreamento natural, sob dossel de floresta, com redução de cerca de $86 \%$ a $89 \%$ de luminosidade, o que pode ter contribuído para a diferença entre os resultados .

Aguiar et al. (2005) verificaram que mudas de Caesalpinia echinata Lam. apresentaram maior diâmetro do caule em condições de pleno sol, quando comparadas com as plantas sob sombreamento de $60 \%$ e $80 \%$, em todos as idades analisadas (12, 18 e 24 meses). Segundo Kozlowski (1962), o aumento do sombreamento diminui a fotossíntese e, consequentemente, a produção de fotoassimilados e reguladores de crescimento, causando redução no diâmetro do caule. $\mathrm{O}$ autor considera ainda que a fotossíntese, aparentemente, guarda uma relação mais direta com o crescimento em diâmetro do que com a altura da planta.

O maior desenvolvimento em altura das mudas ocorreu no ambiente com 50\% de luminosidade, independentemente do substrato utilizado (Figura 2).

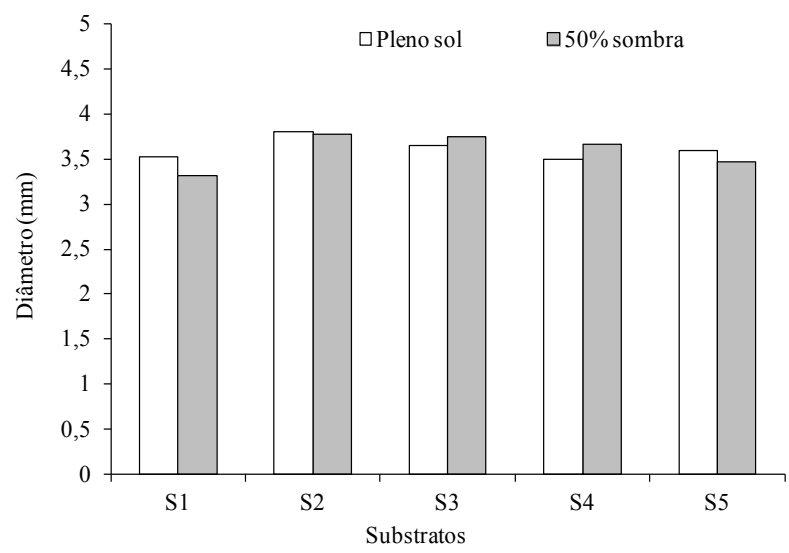

Figura 1. Diâmetro das mudas de Caesalpinia ferrea nos diferentes substratos e ambientes. $\mathrm{S} 1=$ arisco; $\mathrm{S} 2=$ arisco + esterco bovino 2:1; S3 = arisco + esterco bovino $3: 1$; $\mathrm{S} 4=$ areia + esterco bovino $2: 1 ; \mathrm{S} 5=$ areia + esterco bovino 3:1. UFERSA, Mossoró, RN, 2009

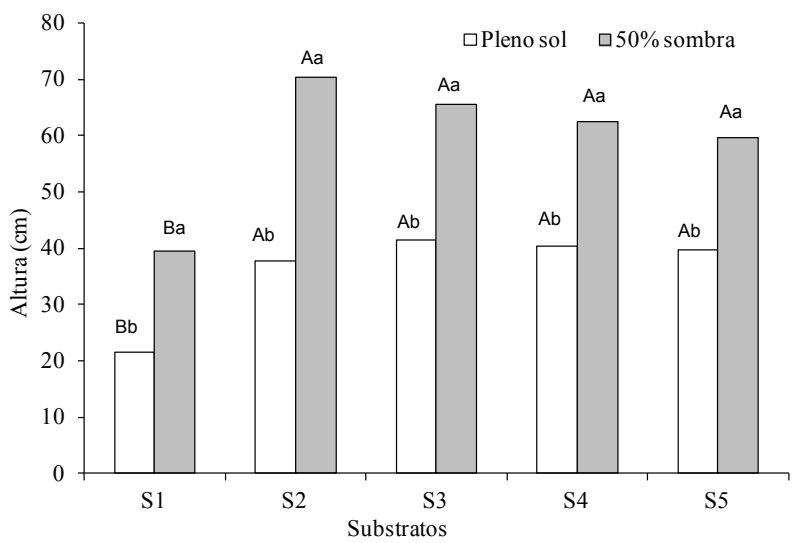

Figura 2. Altura das mudas de Caesalpinia ferrea nos diferentes substratos e ambientes. $\mathrm{S} 1=$ arisco; $\mathrm{S} 2=$ arisco + esterco bovino $2: 1 ; \mathrm{S} 3=$ arisco + esterco bovino $3: 1 ; \mathrm{S} 4=$ areia + esterco bovino 2:1; $\mathrm{S} 5=$ areia + esterco bovino 3:1. As letras maiúsculas comparam os tratamentos dentro da condição de luz, e as minúsculas, entre as condições de luz, pelo teste Scott Knott ( $<<0,05)$. UFERSA, Mossoró, RN, 2009. 
Siebeneichlen et al. (2008) verificaram em mudas de Tabebuia heptaphylla, cultivadas em ambiente de $50 \%$ de luminosidade, maior crescimento em altura do que nas cultivadas em pleno sol. Melo \& Cunha (2008) consideram que a altura da parte aérea apresenta comportamento inversamente proporcional aos níveis de luminosidade recebidos pelas plantas, e o rápido desenvolvimento obtido pelas mudas sombreadas devese à busca de luminosidade pelas plantas, sendo este comportamento comum em áreas florestais, onde há competitividade entre as espécies. Em resultados obtidos para moreira e fedegoso , Almeida et al. (2005) também observaram que a maior altura em espécies lenhosas ocorre em condições sombreadas.

As mudas de Jucá apresentaram maior massa seca da parte aérea (Figura 3A) quando produzidas em ambiente com $50 \%$ de luz e com substrato contendo esterco bovino. A biomassa das raízes também apresentou as maiores médias quando foram utilizados substratos contendo esterco bovino na composição. No entanto, estes resultados ocorreram no ambiente a pleno sol (Figura 3B).

Possivelmente, a matéria orgânica contida nos substratos com esterco bovino supriu as necessidades nutricionais exigidas pelas mudas, pois foi verificado, 0,0 (zero) cmolc $\mathrm{dm}^{-3}$ de $\mathrm{Al}^{3+}$ e altos teores de $\mathrm{Ca}^{2+}$, $\mathrm{Mg}^{2+}, \mathrm{P}$ e K $\mathrm{K}^{+}$(Tabela 1), considerados bons, segundo recomendações para uso de corretivos e fertilizantes da Comissão de Fertilidade do Solo do Estado de Minas Gerais (1999). Segundo Araújo Neto et al. (2002), os substratos que contém adequada quantidade de matéria orgânica apresentam boa capacidade de retenção de água e aeração para a planta.

Por outro lado, o substrato arisco apresentou valores considerados muito baixos para $\mathrm{P}$, baixos para $\mathrm{K}^{3+}$, e, médios para $\mathrm{Ca}^{2+}, \mathrm{Mg}^{2+} \mathrm{e}^{3+}$ (Comissão de Fertilidade do Solo do Estado de Minas Gerais, 1999). Para Meurer et al. (2004), quanto maior a quantidade de resíduos orgânicos no solo, maior é a quantidade de alumínio complexado, tanto na fase sólida como na solução do solo. O alumínio na forma de cátion trocável $\left(\mathrm{Al}^{3+}\right)$ pode ser tóxico para muitas espécies vegetais, afetando a morfologia das raízes, o que influi diretamente na absorção dos nutrientes e da água o que, talvez, possa ter ocorrido neste experimento.

Quando se usou esterco bovino nos substratos e a produção das mudas ocorreu sob 50\% de luminosidade, a área foliar das mudas foi maior (Figura 4). Larcher (2000) afirma que as plantas sob baixa luminosidade tendem a expandir o limbo foliar, aumentando a área de captação de luz. Verificou-se, também, que houve uma tendência de maior biomassa total para as mudas produzidas neste ambiente, resultando em plantas mais vigorosas.

Siebeneichlen et al. (2008) verificaram que há uma tendência maior de expansão da área foliar no ambiente com $50 \%$ de luminosidade e sombra natural do que em pleno sol. A sombra natural considerada por estes autores foi a produzida sob área foliar remanescente de vegetação nativa de Cerrado. Essa expansão
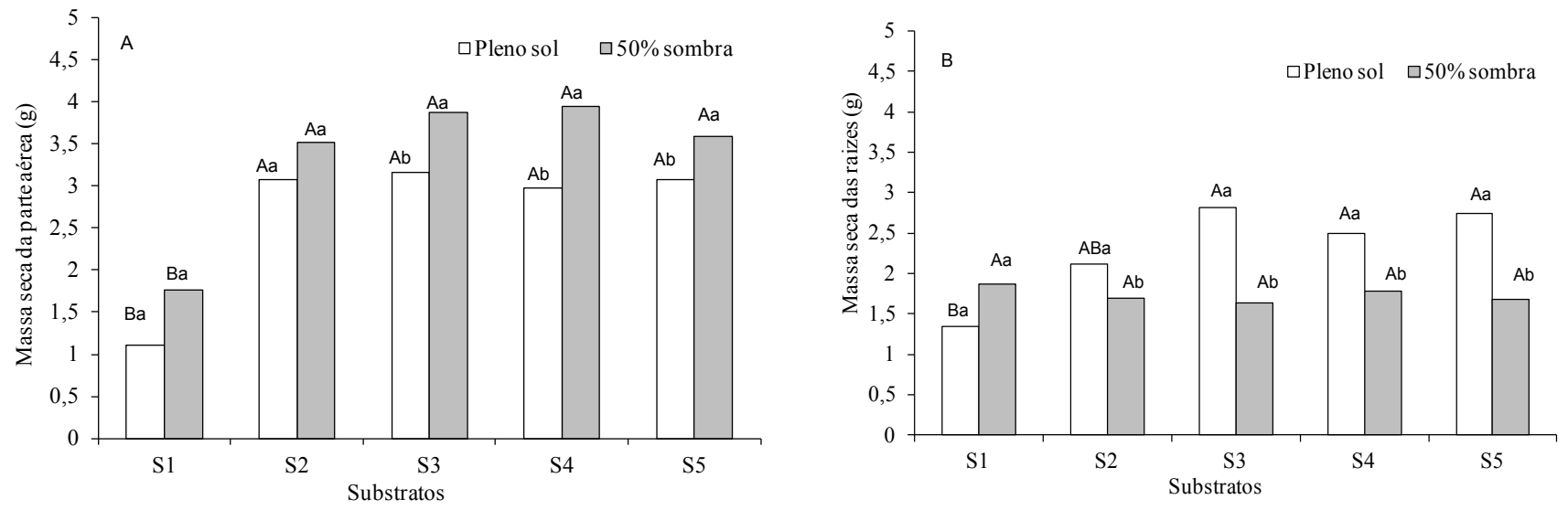

Figura 3. Massa seca da parte aérea (A) e das raízes (B) de mudas de Caesalpinia ferrea nos diferentes substratos e ambientes. $\mathrm{S} 1=\operatorname{arisco} ; \mathrm{S} 2=$ arisco + esterco bovino $2: 1 ; \mathrm{S} 3=$ arisco + esterco bovino $3: 1 ; \mathrm{S} 4=$ areia + esterco bovino $2: 1 ; \mathrm{S} 5=$ areia + esterco bovino $3: 1$. As letras maiúsculas comparam os tratamentos dentro da condição de luz, e as minúsculas, entre as condições de luz, pelo teste Scott Knott ( $\mathrm{p}<0,05)$. UFERSA, Mossoró, RN, 2009. 
remete à habilidade da espécie em utilizar a radiação fotossinteticamente ativa e alocar os fotoassimilados. A obtenção da área foliar foi, portanto, importante para avaliar o desenvolvimento de mudas em diferentes substratos e condições de luminosidade.

Houve diferença significativa para o índice de qualidade de Dickson nas mudas produzidas entre as condições de luz, em todos os substratos (Figura 5).

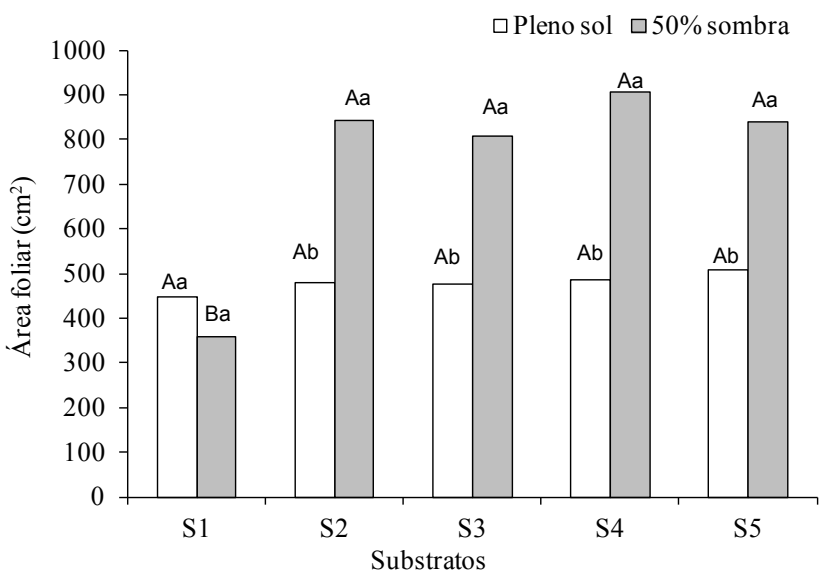

Figura 4. Área foliar de mudas de Caesalpinia ferrea nos diferentes substratos e ambientes. $\mathrm{S} 1=$ arisco; $\mathrm{S} 2=$ arisco + esterco bovino $2: 1 ; \mathrm{S} 3=$ arisco + esterco bovino $3: 1 ; \mathrm{S} 4=$ areia + esterco bovino $2: 1 ; \mathrm{S} 5=$ areia + esterco bovino $3: 1$. As letras maiúsculas comparam os tratamentos dentro da condição de luz, e as minúsculas, entre as condições de luz, pelo teste Scott Knott ( $\mathrm{p}<0,05)$. UFERSA, Mossoró, RN, 2009.

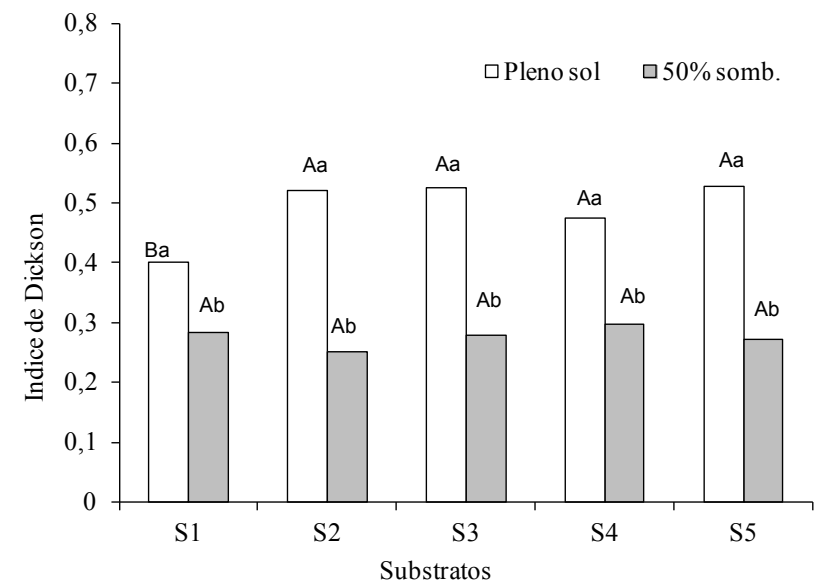

Figura 5. Índice de qualidade de Dickson para mudas de Caesalpinia ferrea nos diferentes substratos e ambientes. As letras maiúsculas comparam os tratamentos dentro da condição de luz, e as minúsculas, entre as condições, de luz pelo teste Scott Knott $(p<0,05)$. UFERSA, Mossoró, RN, 2009
No cálculo desse índice são considerados robustez e o equilíbrio de distribuição de biomassa da muda, ponderando resultados de atributos importantes na avaliação de sua qualidade, sendo um índice de confiança muito utilizado, mas de difícil determinação por envolver parâmetros destrutivos (Gomes et al. 2003). Hunt (1990) propõe um índice de, no mínimo, 0,20 , por ser um bom indicador para as espécies florestais, sendo que, quanto maior o índice encontrado, melhor será o padrão de qualidade das mudas. Neste trabalho, destacou-se a condição a pleno sol, com médias superiores ao valor mínimo de 0,20 , o que caracteriza a boa qualidade das mudas formadas.

A relação entre a altura da planta e o diâmetro do coleto das mudas (H/D) foi maior, independentemente do substrato na condição de sombreamento (Tabela 2). Segundo Gomes et al. (2002), tal relação é também denominada de quociente de robustez, sendo considerada uma das características morfológicos fundamentais para inferir sobre a qualidade de mudas de espécies florestais, pois fornece informações de quanto delgada está a muda. Quanto menor for o valor deste índice, maior será a capacidade das mudas sobreviverem e se estabelecerem no campo (Gomes \& Paiva, 2004), desde que as outras características avaliadas estejam entre os valores aceitáveis.

A relação massa seca da parte aérea/massa seca (MSA/ MSR) foi maior nas mudas produzidas nos substratos com esterco e na condição de pleno sol, com exceção das mudas produzidas na condição de $50 \%$ de luminosidade, em que não houve diferença entre as médias. Conforme Parviainem (1981), a relação de MSA/MSR pode ser considerada um índice eficiente e seguro para avaliar a qualidade de mudas.

Assim, os resultados obtidos no presente estudo, aliados a uma boa qualidade dos torrões, firmeza e agregação, e a facilidade de liberação das mudas das embalagens, constatados no viveiro durante as avaliações, indicam que a utilização de esterco bovino é adequada para a produção de mudas de Caesalpinia ferrea.

Os substratos constituídos pelas maiores doses de esterco bovino proporcionaram melhores características morfológicas para biomassa da parte aérea e das raízes. E os maiores valores da relação entre a biomassa da parte aérea e das raízes foram verificados na condição de pleno sol. 
Tabela 2. Relações entre variáveis obtidas em mudas de Caesalpinia ferrea nos diferentes substratos e ambientes. UFERSA, Mossoró, RN, 2009.

\begin{tabular}{ccccccc}
\hline Variáveis & & S1 & S2 & S3 & S4 & S5 \\
\hline H/D & Pleno sol & $61,22 \mathrm{Bc}$ & $99,60 \mathrm{Bb}$ & $113,83 \mathrm{Ba}$ & $115,14 \mathrm{Ba}$ & $110,23 \mathrm{Ba}$ \\
& $50 \%$ somb. & $118,67 \mathrm{Ab}$ & $186,24 \mathrm{Aa}$ & $173,06 \mathrm{Aa}$ & $170,23 \mathrm{Aa}$ & $172,04 \mathrm{Aa}$ \\
\hline MSPA/MSR & Pleno sol & $0,83 \mathrm{Ab}$ & $1,45 \mathrm{Ba}$ & $1,12 \mathrm{Ba}$ & $1,19 \mathrm{Ba}$ & $1,11 \mathrm{Ba}$ \\
& $50 \%$ somb. & $0,94 \mathrm{Ab}$ & $2,08 \mathrm{Aa}$ & $2,37 \mathrm{Aa}$ & $2,21 \mathrm{Aa}$ & $2,13 \mathrm{Aa}$ \\
\hline
\end{tabular}

$\mathrm{S} 1=$ arisco; $\mathrm{S} 2=$ arisco + esterco bovino 2:1; $\mathrm{S} 3=$ arisco + esterco bovino $3: 1 ; \mathrm{S} 4=$ areia + esterco bovino 2:1; $\mathrm{S} 5=$ areia + esterco bovino $3: 1$.

$\mathrm{H} / \mathrm{D}=$ altura da planta/diâmetro do coleto; MSPA/MSR = massa seca da parte aérea/massa seca da raiz. As letras maiúsculas comparam os tratamentos dentro da condição de luz, e as minúsculas, entre as condições de luz, pelo teste Scott Knott (p<0,05). UFERSA, Mossoró, RN, 2009.

\section{Conclusões}

Mudas de jucá (Caesalpinia ferrea) devem ser produzidas em substratos com esterco bovino, em ambiente a pleno sol, nas condições em que o experimento foi realizado.

\section{Agradecimentos}

Ao Conselho Nacional de Desenvolvimento Científico e Tecnológico (CNPq), pela bolsa de Produtividade concedida ao $2^{\circ}$ autor.

\section{Referências}

AGUIAR, F. F. A.; KANASHIRO, S.; TAVARES, A. R.; PINTO, M. M.; STANCATO, G. C.; AGUIAR, J.; NASCIMENTO, T. D. R. Germinação de sementes e formação de mudas de Caesalpinia echinata Lam. (pau-brasil): efeito de sombreamento. Revista Árvore, Viçosa, MG, v. 29, n. 6, p. 871-875, 2005.

ALMEIDA, S. M. Z.; SOARES, A. M.; CASTRO, E. M.; VIEIRA C. V.; GAJEGO E. B. Alterações morfológicas de biomassa em plantas de espécies florestais sob diferentes condições de sombreamento. Ciência Rural, Santa Maria, RS, v. 35, n. 1, p. 62-68, 2005.

ARAUJO NETO, J. C.; AGUIAR, I. B.; FERREIRA, V. M.; RODRIGUES, T. J. D. Temperaturas cardeais e efeito da luz na germinação de sementes de mutamba. Revista Brasileira de Engenharia Agrícola e Ambiental, Campina Grande, v. 6, n. 3, p. 460-465, 2002.

BARROS JUNIOR, A. P. Desempenho agronômico do bicultivo da alface em sistemas consorciados com cenoura em faixa sob diferentes densidades populacionais. Horticultura Brasileira, Brasília, DF, v. 23, n. 3, p. 712-717, 2005.

COMISSÃO DE FERTILIDADE DO SOLO DO ESTADO DE MINAS GERAIS. Recomendações para o uso de corretivos e fertilizantes em Minas Gerais: $5^{\mathrm{a}}$ aproximação. Lavras, MG, 1999. $359 \mathrm{p}$.

COSTA, E. C.; D'AVILA, M.; CANTARELLI, E. B.; MURARI, A. B.; MANZONI, C. G. Entomologia florestal. Santa Maria, RS: Ed. da UFSM, 2008. 240 p.
DIAS-FILHO, M. B. Physiological response of Solanum crinitum Lam. to contrasting light environments. Pesquisa Agropecuária Brasileira, Brasília, DF, v. 32, n. 8, p. 789-796, 1997.

DUCKE, A. As leguminosas de Pernambuco e Paraíba. Memórias do Instituto Oswaldo Cruz, Rio de Janeiro, v. 51, p. 417-461, 1953. Disponível em: <http://memorias.ioc.fiocruz.br/pdf/Tomo51/ tomo51(f1)_422-466.pdf>. Acesso: 15 ago. 2009.

DICKSON, A.; LEAF, A. L.; HOSNER, J. F. Quality appraisal of white spruce and white pine seedling stock in nurseries. Forest Chronicle, Mattawa, ON, v. 36, p. 10-13, 1960.

FACHIM, E.; GUARIM, V. L. M. S. Conservação da biodiversidade: espécies da flora de Mato Grosso. Acta Botanica Brasilica, Feira de Santana, v. 9, n. 2, p.281-302, 1995.

FERNANDES, P. D. Análise de crescimento e desenvolvimento vegetal. Campina Grande: Departamento de Engenharia Agrícola, UFPB, 2000. 22 p.

FONSECA, E. P.; VALÉRI, S. V.; MIGLIORANZA, E.; FONSECA, N. A. N. COUTO, L. Padrão de qualidade de mudas de Trema micrantha (L.) Blume produzidas sob diferentes períodos de sombreamento. Revista Árvore, Viçosa, MG, v. 26, n. 4, p. 515-523, 2002.

GOMES, J. M.; PAIVA, H. N. Viveiros florestais: propagação sexuada. 3. ed. Viçosa, MG: UFV, 2004. 116 p.

GOMES, J. M.; COUTO, L.; LEITE, H. G.; XAVIER, A.; GARCIA, S. L. R. Parâmetros morfológicos na avaliação de qualidade de mudas de Eucalyptus grandis. Revista Árvore, Viçosa, MG, v. 26, n. 6, p. 655-664, 2002.

GOMES, J. M.; COUTO, L.; LEITE, H. G.; XAVIER, A.; GARCIA, S. L. R. Crescimento de mudas de Eucalyptus grandis em diferentes tamanhos de tubetes e fertilização N-P-K. Revista Árvore, Viçosa, MG, v. 27, n. 2, p. 113-127, 2003.

GONÇALVES, E. O.; PAIVA, H. N.; NEVES, J. C. L.; GOMES, J. M. Crescimento de mudas de sansão-do-campo (Mimosa caesalpiniaefolia Benth.) sob diferentes doses de macronutrientes. Scientiae Forestalis, Piracicaba, SP, v. 38, n. 88, p. 599-609, 2010.

HUNT, G. A. Effect of stryrblock design and Cooper treatment on morphologhogy of conifer seedlings. In: TARGET SEEDLINGS SYMPOSIUM MEETING OF THE WESTERN FOREST NURSERY ASSOCIATIONS, Rosenberg, 1990. Proceedings... Fort Collins: United States Department of Agriculture, Forest Service, 1990. p. 218-222. 
KOZLOWSKI, T. T. Tree growth. New York: The Ronad Press. 1962. p. 149-170.

LARCHER, W. Ecofisiologia vegetal. São Carlos: RIMA, 2000. $531 \mathrm{p}$.

LIMA, J. D.; SILVA, B. M. S.; MORAES, W. S.; DANTAS, A. A. V.; ALMEIDA, C. C. Efeitos da lùminosidade no crescimento de mudas de Caesalpinia ferrea Mart. ex Tul. (Leguminosae, Caesalpinoideae). Acta Amazônica, Manaus, v. 38, n. 1, p. 5-10, 2008.

LORENZI, H.; MATOS, F. J. A. A. Plantas medicinais no Brasil: nativas e exóticas. Nova Odessa: Editora Plantarum, 2008. 544 p.

MAIA, G. N. Caatinga: árvores e arbustos e suas utilidades. São Paulo: D\&Z, 2004. 413 p.

MATTOS, L. R. S. Identificação e caracterização das argamassas para revestimento externo utilizado na cidade de Belém-PA. 2001. 146 f. Dissertação (Mestrado em Engenharia Civil) - Universidade Federal do Rio Grande o Sul, Porto Alegre.

MELO, R. R.; CUNHA, M. C. L. Crescimento inicial de mudas de mulungu (Erythrina velutina Wild.) sob diferentes níveis de luminosidade. Ambiência, Guarapuava, PR, v. 4, n. 1, p. 67-77, 2008.

MEURER, E. J.; RHENHEIMER, D.; BISSANI, C. A. Fenômenos de sorção em solos. In: MEURER EJ. Fundamentos de química do solo. Porto Alegre: GENESIS, 2004. p.73-99.

MORAES NETO, S. P.; GONÇALVES, J. L. M. Efeitos da luminosidade sobre o estado nutricional de mudas de seis espécies arbóreas que ocorrem na mata atlântica. Revista Árvore, Viçosa, MG, v. 25, n. 1, p. 29-38, 2001.

NEGREIROS, J. R. S.; ÁLVARES, V. S.; BRAGA, L. R.; BRUCKNER, C. H. Diferentes substratos na formação de mudas de maracujazeiro-amarelo. Ceres, Viçosa, MG, v. 51, n. 294, p. 243-343, 2004.
OLIVEIRA, R. P.; RADMANN, E. B.; SCIVITTARO, W. B. Mudas de citros. Pelotas: Embrapa Clima Temperado, 2005. (Embrapa Clima Temperado. Sistema de Produção, 1).

PARVIAINEN, J. V. Qualidade e avaliação de qualidade de mudas florestais. In: SEMINÁRIO DE SEMENTES E VIVEIROS FLORESTAIS, 1., 1981, Curitiba. Anais... Curitiba: FUPEF, 1981. p. 59-90.

RIBEIRO JUNIOR, J. I.; MELO, A. L. P. Guia prático para utilização do SAEG. Viçosa, MG: Editora Independente, 2009, 287 p.

SALCEDO, I. H.; SAMPAIO, E. V. S. B. Matéria orgânica do solo no Bioma Caatinga. In: SANTOS, G. A.; SILVA, L. S.; CANELLAS, L. P.; CAMARGO, F. A. O. Fundamentos da matéria orgânica do solo: ecossistemas tropicais e subtropicais. Porto Alegre: Gráfica Metrópole, 2008. p. 419-441.

SANTARELLI, E. G. Produção de mudas de espécies nativas para florestas ciliares. In: RODRIGUES, R. R.; LEITÃO FILHO, H. Matas ciliares: conservação e recuperação. São Paulo: EDUSP/ FAPESP, 2001. p. 313-318.

SANTOS, L. W.; COELHO, M. F. B. Cobertura verde e uso de resíduo orgânico em Lafoensia pacari A.St.- Hil. Revista Brasileira de Plantas Medicinais, Botucatú, SP, v. 10, n. 3, p. 16-23, 2008.

SIEBENEICHLEN, S. C.; FREITAS, G. A.; SILVA, R. R.; ADORIAN, G. C.; CAPELLARI, D. Características morfofisiológicas em plantas de Tabebuia heptaphyilla (Vell.) Tol. em condições de luminosidade. Acta Amazonica, Manaus, AM, v. 38, n. 3, p. 467-472, 2008.

SILVA, R. A.; NETO, F. B.; NUNES, G. H. S.; NEGREIROS, M. Z. Estimação de parâmetros genéticos e correlações de famílias de meios-irmãos de melões Orange Red Flesh HTC 01. Caatinga, Mossoró, RN, v. 15, n. 1/2, p. 43-48, 2002. 